\title{
CORRESPONDENCE
}

\author{
e
}

\author{
Outpatient follow-up after curative \\ surgery for carcinoma of the large \\ bowel \\ I S L Loudon, DM. . . . . . . . . . . . . . . 1118 \\ Management of acute illness in infants \\ before admission to hospital \\ D J G Bain, FRCGP........... 1118 \\ Recognising child abuse \\ J E Oliver, MRCPSYCH; R J Flanagan, BSC, \\ and $\mathrm{G} N$ Volans, $\mathrm{MD} . \ldots \ldots \ldots \ldots \ldots \ldots . \ldots 1119$ \\ Assessment of fitness for surgical \\ procedures \\ J J Henderson, FFarcs............. 1119 \\ Weaning and diarrhoea in the Gambia \\ M G M Rowland, MRCP.............. 1119 \\ Second-best prostatectomy? \\ J M G Wilson, FRCP; P J B Smith, FRCs; \\ R Bewick, FrCs................ 1119
}

Interaction between lithium and

carbamazepine

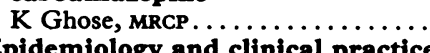

Epidemiology and clinical practice

E D Acheson, FRCP, and others ......... 1122

Points Haemoptysis and clonorchiasis (D

Engel); Beta-blockers and bioavailability

(E H L Harries); Hypokalaemia and diuretics (J L C Dall); Surgical treatment of prolapsed lumbar disc ( $\mathrm{K}$ Norcross); The passing of a custom? Revd W P Hedgcock); Doctors and compulsory procedures (S S Bakhshi); Health hazards from the nuclear industry (Nini E

Ettlinger); Acceleration due to gravity

(T P Usherwood)................ 1123

Correction: Hirsutism and virilisation

(Rentoul) ..................... 1123

We may return unduly long letters to the author for shortening so that we can offer readers as wide a selection as possible. We receive so many letters each week that we have to omit some of them. Letters must be signed personally by all their authors. We cannot acknowledge their receipt unless a stamped addressed envelope or an international reply coupon is enclosed.

\section{Outpatient follow-up after curative surgery for carcinoma of the large bowel}

SIR,-The paper by Mr John P S Cochrane and others (1 March, p 593) illuminates one of the more unsatisfactory aspects of NHS practice: the follow-up of patients admitted to hospital for major illness. What is the reality so far as long-term care is concerned?

During the initial stages of clinical diagnosis, investigation, operation, and discharge home when the respective areas of clinical responsibility are clearly marked out, the patient gets to know and to have confidence in all his doctors. Then he attends a long series of outpatient appointments at intervals that increase to six months, a year, or two years. At these he usually sees a series of new, young, and strange junior doctors. If he has consulted his GP between these appointments he may receive contrary advice and he begins to suspect (quite rightly) that, in contrast to when he was first ill, communication between his GP and the hospital is less than perfect. Sadly, he finds his confidence eroded and he is unsure to whom he should turn. All too often the existence of the follow-up system has diminished his GP's feeling of involvement and responsibility for that particular illness. By this stage hospital follow-up cannot be justified as necessary for the surgeon's experience, or for research or teaching-or even for the early detection of late complications since the interval between appointments is too long.

Who, then, should be responsible? Some patients, for reasons of hospital techniques or special expertise, need careful follow-up at hospital; many, probably most, do far better entirely under the care of their GP; while a few have built such a lifeline to the hospital that, whoever sees them there, shared follow-up is sensible. There are no golden rules. Follow-up, especially in cancer, needs as much sensitivity, thought, and individual planning as care on the ward, because it is impossible for two doctors to care for a patient with a long-term illness unless they are working very closely together and one of them is clearly in charge. It is sad that in this excellent paper the GP is never mentioned. It ought to bebut seldom is-routine, if dual care is necessary, for the GP and hospital doctor to communicate at each follow-up so that each knows what the other is saying.

Improvement in the long-term care of serious illness depends on much better co-operation and understanding between the general practitioner and the hospital. Neither can be wholly responsible for all cases, but it must be crystal clear in each individual case who is.

Health Centre,

Wantage, Oxon OX12 7AY

IRVINE S L LOUDON

Management of acute illness in infants before admission to hospital

SIR,-In their survey of the management of acute illness in infants before admission to hospital Dr A N Stanton and his colleagues (29 March, p 897) have chosen a narrow interpretation of their results, and have omitted a number of important points which are worthy of consideration. From the figures presented the child population at risk was in the region of 9000 infants, and the 150 children admitted to hospital represent a very small proportion of that total. How representative were these 150 children? What was the social class distribution of the infants admitted ?

There is no attempt in the article to give an account of the spectrum of illness from which the hospital cases were produced. Children under 1 year of age are seen, on average, eight times a year by a general practitioner, 1 and in the six-month period of the study described the population aged under 1 year, which numbered around 9000 infants, would have generated approximately 36000 contacts with their general practitioners. The majority of these consultations would have been accounted for by the common symptoms described in the article. The study provides no details of the management and follow-up procedures adopted for the large number of children not admitted to hospital.

It would also have been helpful to know if there was any relationship between children admitted to hospital and the geographical location of the general practitioners and their patients. The presence or absence of zoning of city practices may have a notable effect on both patients' and doctors' behaviour when follow-up or hospital admission is being considered. The detailed inquiries about admissions might have been enhanced by including measurement of the type and size of practices from which the children came. A surprising omission in the results described is the lack of information about the eventual outcome for the children admitted, and it would seem reasonable to suggest that this evidence is crucial to any interpretation of management prior to admission to hospital.

While there is no room for complacency in the general practice management of acute illness in young children, the study reported does not provide sufficient evidence to support the suggestion that more frequent follow-up by general practitioners and health visitors is required. If there is a belief among paediatricians that more careful follow-up of sick infants will lead to better outcomes for children and their parents, then carefully controlled trials of different follow-up regimens are required before making specific recommendations.

University Department of General Practice,

Foresterhill Health Centre, ${ }^{1}$ Fry J. Profiles of disease. Edinburgh: E and S Living-
stone, 1966 . 